\title{
Combined grazing incidence RBS and TEM analysis of luminescent nano-SiGe/SiO 2 multilayers
}

\author{
A. Kling , A. Rodríguez , J. Sangrador , M.I. Ortiz , T. Rodríguez , \\ C. Ballesteros , J.C. Soares \\ Centro de Física Nuclear da Universidade de Lisboa, Av. Prof. Gama Pinto 2, 1649-003 Lisboa, Portugal \\ Instituto Tecnológico e Nuclear, Estrada Nacional n'10, 2686-953 Sacavém, Portugal \\ Departamento de Tecnología Electrónica, ETSI de Telecomunicación, Universidad Politécnica de Madrid, 28040 Madrid, Spain \\ Departamento de Física, Escuela Politécnica Superior, Universidad Carlos III, 28911 Leganés, Madrid, Spain
}

\begin{abstract}
Multilayer structures with five periods of amorphous $\mathrm{SiGe}$ nanoparticles/SiO $\mathrm{S}_{2}$ layers with different thickness were deposited by Low Pressure Chemical Vapor Deposition and annealed to crystallize the SiGe nanoparticles. The use of grazing incidence RBS was necessary to obtain sufficient depth resolution to separate the signals arising from the individual layers only a few nm thick. The average size and areal density of the embedded SiGe nanoparticles as well as the oxide interlayer thickness were determined from the RBS spectra. Details of eventual composition changes and diffusion processes caused by the annealing processes were also studied. Transmission Electron Microscopy was used to obtain complementary information on the structural parameters of the samples in order to check the information yielded by RBS. The study revealed that annealing at $900^{\circ} \mathrm{C}$ for $60 \mathrm{~s}$, enough to crystallize the SiGe nanoparticles, leaves the structure unaltered if the interlayer thickness is around $15 \mathrm{~nm}$ or higher.
\end{abstract}

Keywords: Nanostructure multilayers; SiGe nanoparticles; LPCVD; Grazing incidence RBS; TEM

\section{Introduction}

$\mathrm{Si}, \mathrm{SiGe}$ and Ge nanoparticles embedded in an oxide matrix are highly interesting for applications in luminescent devices compatible with CMOS technology A promising method for the production of this kind of structures is the deposition of amorphous SiGe nanoparticles embedded in $\mathrm{SiO}_{2}$ using a conventional hot tube Low Pressure Chemical Vapor Deposition reactor operating at low temperatures followed by a thermal treatment to crystallize them. These structures exhibit luminescent emission peaking in the blue-violet at $400 \mathrm{~nm}$ The influence of the thermal treatment processes on the structure of the samples has to be investigated in order to optimize the annealing conditions to get the maximum luminescence intensity. Since the luminescence in single discontinuous layers is limited by the number of nanoparticles that can be placed in a plane, the use of multilayer structures is of high interest to increase the light output In the present study, the structural properties of as-deposited and annealed multilayers with different nanoparticle sizes and $\mathrm{SiO}_{2}$ interlayer thicknesses have been investigated and the eventual structural degradation due to the annealing has been analyzed. 


\section{Experimental details}

Multilayer structures with five layers of amorphous SiGe nanoparticles and six identical $\mathrm{SiO}_{2}$ layers were deposited on Si wafers in a continuous process using a commercial LPCVD reactor. The total pressure and temperature were kept constant at $50 \mathrm{mTorr}$ and $390^{\circ} \mathrm{C}$, respectively. The discontinuous $\mathrm{SiGe}$ layers (i.e. the $\mathrm{SiGe}$ nanoparticle containing layers) were deposited using $\mathrm{Si}_{2} \mathrm{H}_{6}$ and $\mathrm{GeH}_{4}$. Keeping a flow ratio of $\mathrm{GeH}_{4} / \mathrm{Si}_{2} \mathrm{H}_{6}=0.82$ allowed a $\mathrm{Ge}$ fraction of $x \approx 0.4$ to be achieved. The $\mathrm{SiO}_{2}$ layers were produced using $\mathrm{Si}_{2} \mathrm{H}_{6}$ and $\mathrm{O}_{2}$ with a flow ratio of $\mathrm{Si}_{2} \mathrm{H}_{6} / \mathrm{O}_{2}=0.2$. The thickness of both types of layers was controlled by the deposition time. More details on the system and on the deposition process can be found elsewhere Samples with multilayer structures combining two different SiGe nanoparticle sizes with thin $(5 \mathrm{~nm})$, intermediate $(15 \mathrm{~nm})$ and thick $(35 \mathrm{~nm}) \mathrm{SiO}_{2}$ interlayers (nominal thickness) were deposited (see Table 1 for the sample identification and their characteristics).

The samples were subjected to heat treatments at temperatures between $700{ }^{\circ} \mathrm{C}$ and $900{ }^{\circ} \mathrm{C}$ in $\mathrm{N}_{2}$ atmosphere and for times up to $60 \mathrm{~s}$ using a Rapid Thermal Annealing (RTA) unit in order to induce crystallization. Sample D was also subjected to annealing in a conventional open tube furnace under $\mathrm{N}_{2}$ atmosphere at temperatures of $900^{\circ} \mathrm{C}$ and $1000^{\circ} \mathrm{C}$ for $1 \mathrm{~h}$ to investigate the eventual degradation for higher temperatures and longer annealing times.

Grazing incidence RBS measurements with a $2 \mathrm{MeV}$ ${ }^{4} \mathrm{He}^{+}$ion beam impinging on the target at angles between $72^{\circ}$ and $82^{\circ}$ were used to obtain sufficiently high depth resolution to separate the signals arising from the different layers and to detect and investigate possible compositional changes. The Si surface barrier detector was located at $160^{\circ}$ with respect to the incident beam in Cornell geometry. Cross-sectional specimens suitable for high-resolution transmission electron microscopy (HRTEM) were prepared by standard procedures. TEM images were obtained using a Philips Tecnai 20F FEG analytical microscope operating at $200 \mathrm{keV}$, equipped with EDX.

Photoluminescence measurements were performed at room temperature using the $315 \mathrm{~nm}$ line of a $\mathrm{He}-\mathrm{Cd}$ laser for excitation.

\section{Results and discussion}

In a first step the as-deposited multilayer structures, which serve as a reference, were characterized by TEM and grazing incidence RBS to determine the composition, diameter and areal density of the embedded SiGe nanoparticles as well as the thickness of the $\mathrm{SiO}_{2}$ interlayers. A model recently developed by the authors using RUMP

for the analysis of RBS spectra of samples containing embedded nanoparticles was used for these purposes. The results of the TEM and RBS studies are summarized in Table 1 showing a good agreement. The size and spatial distribution of the nanoparticles located in the different layers exhibit a good uniformity and the thickness of the different oxide interlayers of each sample is repetitive. The EDX spectra obtained in very thin areas of the asdeposited samples as well as the RBS spectra fittings are consistent with the nominal value of the Ge fraction, $x$ $\approx 0.4$. Unless otherwise specified, the data obtained by RBS are used from now on throughout the text.

The TEM micrographs of three of the samples (B, C and D) after RTA treatment at $900{ }^{\circ} \mathrm{C}$ for $60 \mathrm{~s}$, shown in Fig. 1, revealed that the morphology of the samples after annealing remains unaltered compared to the as-deposited ones (not shown), preserving the nanoparticle size and the average nanoparticle density. In sample B (and also in A, not included), due to the two-dimensional projection of the three-dimensional sample, the layers appear to be continuous. Higher magnification studies carried out in very thin areas indicate that the layers are discontinuous, although the areal density of nanoparticles could not be estimated because the nanoparticles appear superimposed to each others in the images. The analysis of the TEM images of samples $\mathrm{C}$ and $\mathrm{D}$ allows the minimum areal density of nanoparticles to be estimated and it is always above $5 \times 10^{11} \mathrm{~cm}^{-2}$ in each layer.

Although the TEM studies indicate that the multilayer structures in these three samples are intact after the RTA treatments, grazing incidence RBS measurements were performed to check for eventual compositional changes that are not detected by TEM.

Fig. 2 shows the RBS spectra of sample A, which has the thinnest $(3-3.3 \mathrm{~nm}) \mathrm{SiO}_{2}$ interlayers and larger nanoparticles (ca. $7 \mathrm{~nm}$ in diameter), in the as-deposited state and after RTA annealing at $800^{\circ} \mathrm{C}$ for $30 \mathrm{~s}$ and $900^{\circ} \mathrm{C}$ for $60 \mathrm{~s}$. The separation of the Ge signals stemming from the nanoparticle layers was only possible using a tilt angle of $\theta=82^{\circ}$. While for annealing at $700^{\circ} \mathrm{C}$ (not shown) and $800^{\circ} \mathrm{C}$ the RBS spectra virtually overlap with the one of the as-deposited sample, after annealing at $900{ }^{\circ} \mathrm{C}$ a strong degradation of the multilayer structure is observed. A detailed analysis of the RBS spectra shows that about half

Table 1

SiGe nanoparticle diameters, areal densities of nanoparticles and $\mathrm{SiO}_{2}$ interlayer thickness determined by TEM and RBS

\begin{tabular}{|c|c|c|c|c|c|}
\hline \multirow[t]{2}{*}{ Sample } & \multicolumn{2}{|l|}{ Values determined by TEM } & \multicolumn{3}{|l|}{ Values determined by RBS } \\
\hline & Nanoparticle diameter $(\mathrm{nm})$ & Interlayer thickness $(\mathrm{nm})$ & Nanoparticle diameter $(\mathrm{nm})$ & Interlayer thickness (nm) & Area density $\left(10^{12} \mathrm{~cm}^{-2}\right)$ \\
\hline $\mathrm{A}$ & $\geqslant 5$ & 5 & 7.0 & $3.0-3.3$ & $1.2-1.3$ \\
\hline D & $3.0-4.5$ & 35 & 4.0 & $33-36$ & 1.2 \\
\hline
\end{tabular}




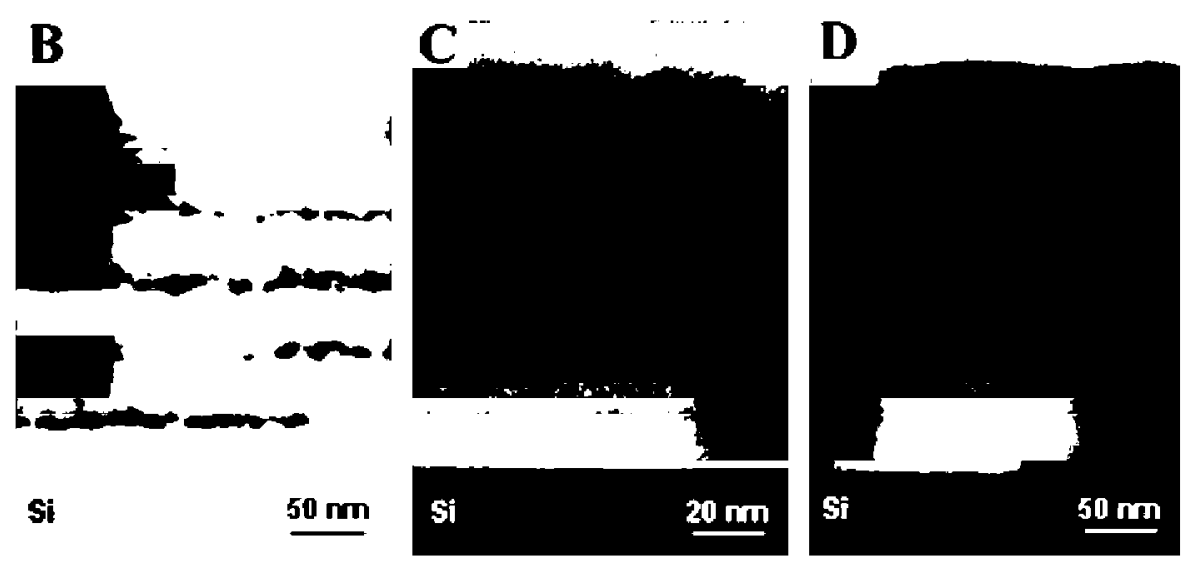

Fig. 1. TEM images of samples B, C and D (see text and Table 1) after RTA at $900{ }^{\circ} \mathrm{C}, 60 \mathrm{~s}$.

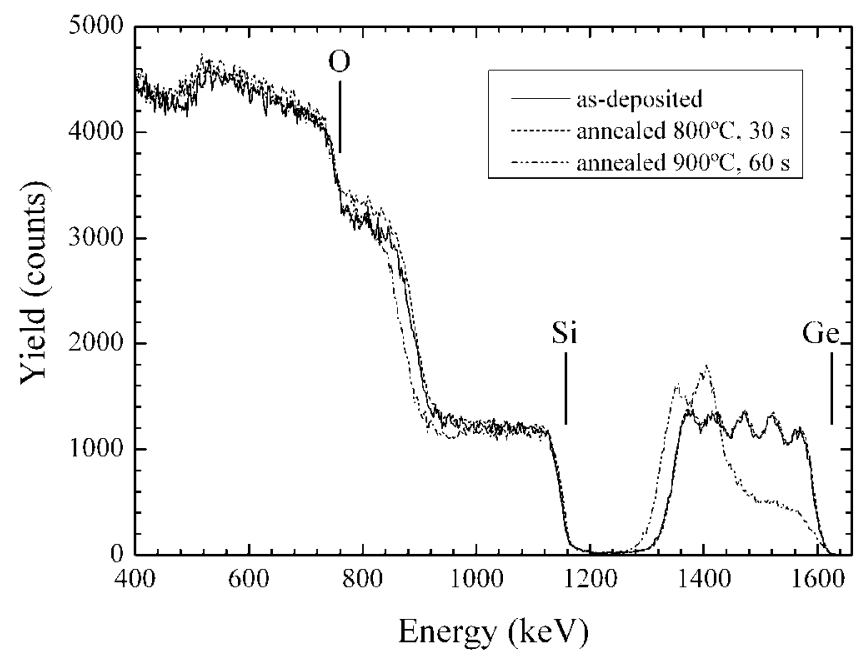

Fig. 2. Grazing incidence RBS spectra $\left(0=82^{\circ}\right)$ of sample A in the asdeposited state and after RTA at $800^{\circ} \mathrm{C}$ and $900^{\circ} \mathrm{C}$.

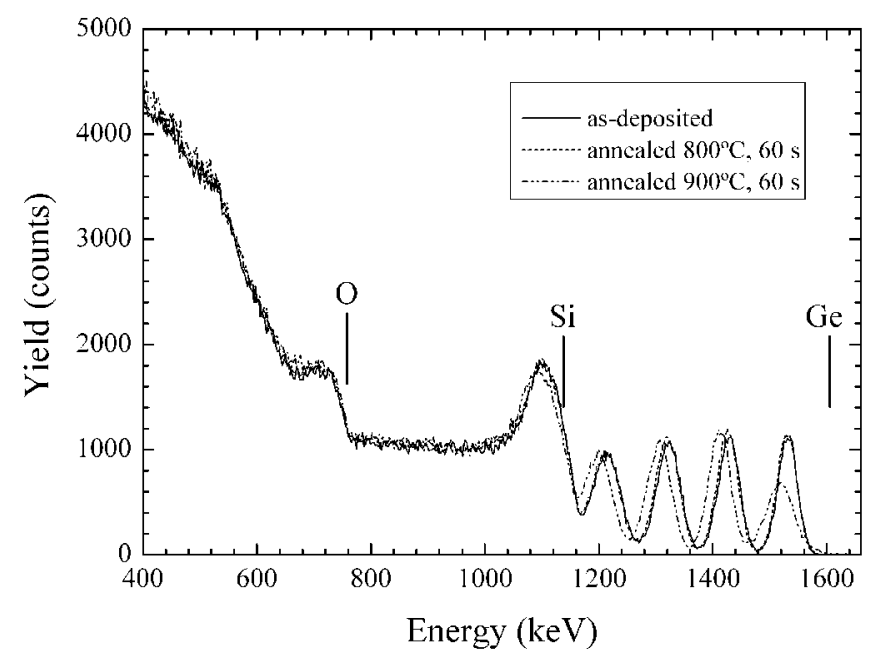

Fig. 3. Grazing incidence RBS spectra $\left(\theta=78^{\circ}\right)$ of sample B in the asdeposited state and after RTA at $800^{\circ} \mathrm{C}$ and $900^{\circ} \mathrm{C}$. of the Ge originally contained in the three top SiGe nanoparticle layers has been lost. One fraction seems to have left the sample by outdiffusion while another fraction has diffused into the adjacent $\mathrm{SiO}_{2}$ interlayers and into the fourth layer from the top. The Ge content of this layer increased significantly with regard to the as-deposited sample as can be seen from the enhanced RBS yield. The fifth layer located next to the $\mathrm{Si}$ substrate has virtually not been affected by the annealing. The results of the RUMP fit using the nanoparticle model indicate that the size of the remaining SiGe nanoparticles in the three top layers has been reduced to an average diameter of about $4 \mathrm{~nm}$.

In the case of sample B, which has nanoparticles with the same average diameter as sample $A($ ca. $7 \mathrm{~nm}$ ) but much thicker $(33-35 \mathrm{~nm}) \mathrm{SiO}_{2}$ interlayers, the RBS spectra (Fig. 3) taken at a tilt angle of $\theta=78^{\circ}$, in this case sufficient to resolve the $\mathrm{SiGe}$ nanoparticle layers, also show that the RTA at $800^{\circ} \mathrm{C}$ leaves the structure unchanged. Compared to sample A the degradation after RTA at $900{ }^{\circ} \mathrm{C}$ for $60 \mathrm{~s}$ is strongly reduced and affects only the SiGe nanoparticle layer located closest to the surface.

The RBS spectra of sample C (Fig. 4), which contains smaller $\mathrm{SiGe}$ nanoparticles (ca. $4 \mathrm{~nm}$ diameter), taken at $\theta=82^{\circ}$ (in order to resolve the SiGe layers despite the $12-15 \mathrm{~nm}$ thick interlayers) show that the RTA at $800^{\circ} \mathrm{C}$ and $900^{\circ} \mathrm{C}$ has virtually no effect on the layer structure with $\mathrm{SiO}_{2}$ interlayers thicker than those of sample A. Indications of a slight $\mathrm{Ge}$ diffusion towards the interface have been found after RTA at $800^{\circ} \mathrm{C}$ for $30 \mathrm{~s}$ using a slightly lower tilt angle of $80.8^{\circ}$ (not shown). Due to the reduced separation of such a thin layer from the last $\mathrm{SiGe}$ layer and the Si substrate at $\theta=82^{\circ}$ and the enhanced straggling at this depth a quantitative determination of the Ge amount at the interface was not feasible.

For sample D (with nanoparticles of around $4 \mathrm{~nm}$ in diameter and $33-36 \mathrm{~nm}$ thick interlayers) after RTA at $800^{\circ} \mathrm{C}$ and $900^{\circ} \mathrm{C}$ for $60 \mathrm{~s}$ the RBS spectra with $\theta=72^{\circ}$ (Fig. 5) show that the general structure of the sample is only slightly altered and that a slight diffusion of $\mathrm{Ge}$ towards the Si substrate occurs. The amount of Ge found 


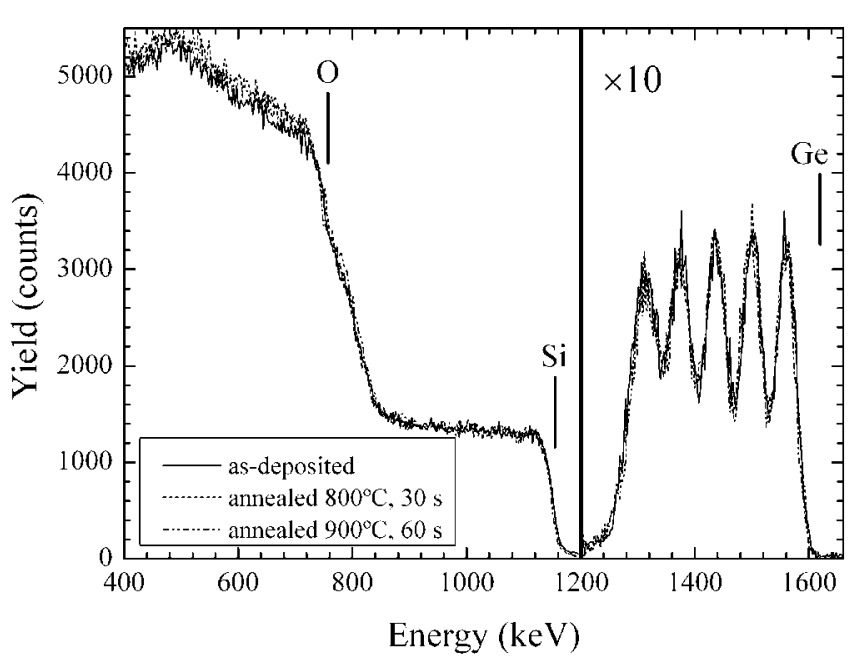

Fig. 4. Grazing incidence RBS spectra $\left(0=82^{\circ}\right)$ of sample $\mathrm{C}$ in the asdeposited state and after RTA at $800^{\circ} \mathrm{C}$ and $900^{\circ} \mathrm{C}$.

at the interface with the Si substrate is $2.2 \times 10^{15} \mathrm{~cm}^{-2}$ and $4.4 \times 10^{15} \mathrm{~cm}^{-2}$ in the samples annealed at $800^{\circ} \mathrm{C}$ and $900^{\circ} \mathrm{C}$, respectively. Annealing of this sample for $1 \mathrm{~h}$ leads at all the investigated temperatures $\left(900^{\circ} \mathrm{C}\right.$ and $\left.1000{ }^{\circ} \mathrm{C}\right)$ to a significant alteration of the multilayer structures as can be seen in the RBS spectra of Fig. 6 . Annealing at $900{ }^{\circ} \mathrm{C}$ leads to the formation of a discontinuous Ge layer (ca. $9 \times 10^{15} \mathrm{~cm}^{-2}$ ) at the interface with the Si substrate, while annealing at $1000^{\circ} \mathrm{C}$ also causes the Ge to diffuse into the substrate. A further interesting effect is that after annealing at $900{ }^{\circ} \mathrm{C}$ for 30 or $60 \mathrm{~s}$ the structure remains almost intact except for the slight Ge diffusion processes, but if the annealing time is increased up to $1 \mathrm{~h}$ or the temperature is raised up to $1000{ }^{\circ} \mathrm{C}$ the layers located close to the $\mathrm{Si}$ substrate are strongly affected by the diffusion while the top layer of nanoparticles is not strongly affected, so the degradation of this specific sample takes place mostly by diffusion from all layers towards the substrate and only

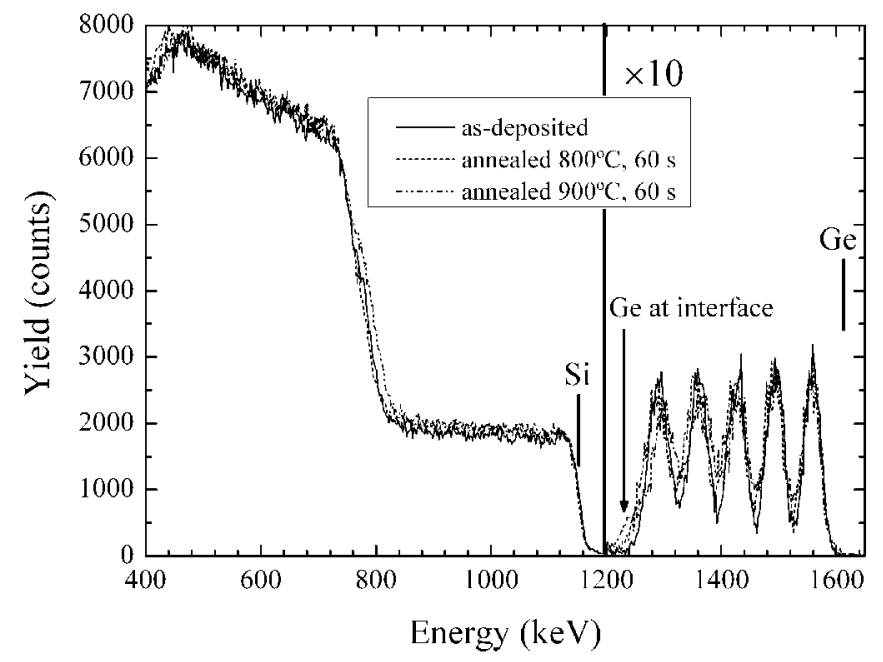

Fig. 5. Grazing incidence RBS spectra $\left(0=72^{\circ}\right)$ of sample D in the asdeposited state and after RTA at $800^{\circ} \mathrm{C}$ and $900^{\circ} \mathrm{C}$.

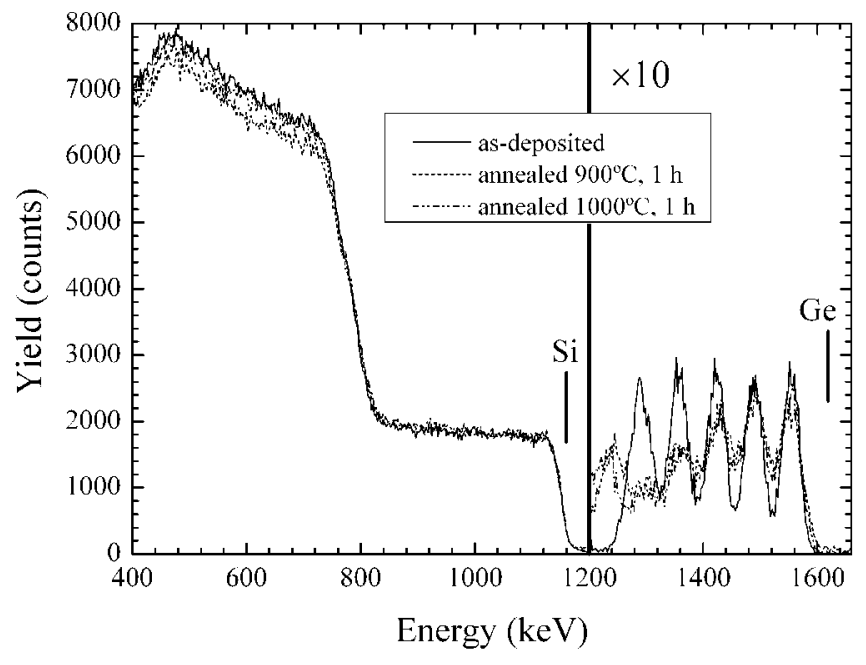

Fig. 6. Grazing incidence RBS spectra $\left(0=72^{\circ}\right)$ of sample D in the asdeposited state and after furnace annealing at $900^{\circ} \mathrm{C}$ and $1000^{\circ} \mathrm{C}$.

slightly towards the outer surface of the sample. In addition to the structural features of the sample, other factors like the enhanced densification of the oxide layers could play a role in the observed behavior.

A recently published study on the optimization of the luminescent properties of these samples shows that the cathodoluminescence intensities of samples B, C and D increase with RTA treatment temperature and time up to $900^{\circ} \mathrm{C}$ and $60 \mathrm{~s}$, respectively. The relative luminescence intensities of these samples are 25 (B), 10 (C) and 300 (D) indicating that the luminescence is optimized by the simultaneous presence of Ge diffusion limiting thick interlayers and small nanocrystals. These results are corroborated by photoluminescence measurements performed at room temperature. Fig. 7 shows the results for sample D which shows the largest luminescence enhancement. Sample A shows a reduced luminescence at these treatment

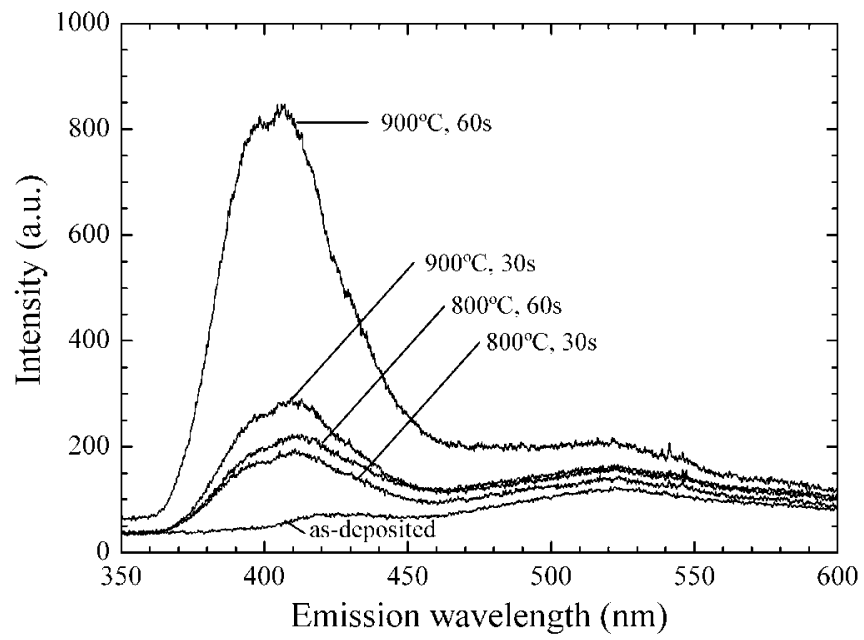

Fig. 7. Photoluminescence spectra for sample $\mathrm{D}$ in the as-deposited state and after RTA at $800^{\circ} \mathrm{C}$ and $900^{\circ} \mathrm{C}$. The excitation wavelength is $315 \mathrm{~nm}$. 
conditions which is a result of the degradation of the multilayer structure.

\section{Conclusions}

RBS characterization of multilayers of SiGe nanoparticles/ $\mathrm{SiO}_{2}$ using grazing angles resolved the signals of the different layers of nanometric thickness in the spectra, thus making possible the analysis of the structure of the samples and the study the effect of the annealing processes on this structure.

The detailed characterization of the important structural properties of $\mathrm{SiGe}$ nanoparticle/ $\mathrm{SiO}_{2}$ multilayer structures (composition, diameter and areal density of the nanoparticles as well as the thickness of the oxide interlayers) has been carried out using a model developed by the authors to produce an input for the RUMP code. The obtained results are in agreement with those derived from the TEM analysis of the samples, which were used as a reference for comparison.

The RBS study revealed that annealing of the multilayers at $900^{\circ} \mathrm{C}$ for $60 \mathrm{~s}$, which are conditions that produce the crystallization of the nanoparticles, keeps the main structural features of the multilayers unaltered if the $\mathrm{SiO}_{2}$ interlayers are thick enough (above $12-15 \mathrm{~nm}$ ).

\section{Acknowledgments}

This work was funded by the Spanish Government through CICYT Project MAT2004-04580-C02 and a common Grant by CRUP (Portugal) and MCT (Spain) in the framework of the Acçôes Integradas/Acciones Integradas Program. TEM work has been carried out at the LABMET of the CAM (Madrid). The authors would like to thank M. Avella and J. Jiménez (Universidad de Valladolid, Spain) for the PL measurements.

\section{References}

M. Zacharias, L.X. Yi, J. Heitmann, R. Scholz, M. Reiche, U. Gösele, Solid State Phenom. 94 (2003) 131.

S.N.M. Mestanza, E. Rodríguez, N.C. Frateschi, Nanotechnology 17 (2006) 4548 .

A. Rodríguez, M.I. Ortiz, J. Sangrador, T. Rodríguez, M. Avella, A.C. Prieto, J. Jimenéz, A. Kling, C. Ballesteros, Phys. Status Solidi (A) 204 (2007) 1639

M.I. Ortiz, J. Sangrador, A. Rodríguez, T. Rodríguez, A. Kling, N. Franco, N.P. Barradas, C. Ballesteros, Phys. Status Solidi (A) 203 (2006) 1284.

A. Kling, M.I. Ortiz, J. Sangrador, A. Rodríguez, T. Rodríguez, C. Ballesteros, J.C. Soares, Nucl. Instr. and Meth. B 249 (2006) 451.

L.R. Doolittle, Nucl. Instr. and Meth. 9 (1985) 344, The latest version of this program can be found at http://www.genplot.com. 